\title{
Degradation and utilisation of chondroitin sulphate by Streptococcus intermedius
}

\author{
H. SHAIN, K. A. HOMER and D. BEIGHTON \\ Oral Microbiology, Royal College of Surgeons Department of Dental Sciences, King's College School of \\ Medicine and Dentistry, Caldecot Road, London SE5 9RW
}

\begin{abstract}
Streptococcus intermedius, part of the 'Streptococcus milleri group', has the ability to produce glycosaminoglycan depolymerising enzymes (hyaluronidase and chrondroitin sulphate depolymerase) which is unique amongst the viridans streptococci and may contribute to their virulence in brain and liver abscesses. The growth of $S$. intermedius strain UNS 35 was studied in basal medium supplemented with chondroitin sulphate $A$ (CS-A, sulphated at position 4 of the $\mathrm{N}$-acetylgalactosamine moiety) or chondroitin sulphate $\mathrm{C}$ (CS-C, sulphated at position 6 of the $\mathrm{N}$-acetylgalactosamine moiety) as the major carbohydrate source. CS-A but not CS-C supported the growth of $S$. intermedius. Extracellular degradation of CS-A resulted in the initial accumulation of 2-acetamido-2deoxy-3-O-( $\beta$-D-gluco-4- $\Delta$ enepyranosyluronic acid)-D-galactose ( $\triangle U A$ GalNAc-0S), and low levels of 2-acetamido-2-deoxy-3-O-( $\beta$-D-gluco-4- $\Delta$ enepyranosyl uronic acid)-4-0sulpho-D-galactose ( $\triangle$ UA GalNAc-4S) in the medium with GalNAc-0S being subsequently utilised during bacterial growth. Metabolic end-products included formate and ethanol but not lactate, indicating that growth was probably carbon-limited. The CS-A contained $30 \%$ CS-C, which was also depolymerised resulting in the formation of 2-acetamido-2-deoxy-3-O-( $\beta$-D-gluco-4- $\Delta$ enepyranosyluronic acid)-6-O-sulpho-D-galactose ( $\triangle$ UA GalNAc-6S) in the culture supernate, but this unsaturated disaccharide was apparently not utilised during growth. The results indicate that $S$. intermedius produced CS-AC depolymerase, which was inducible and extracellular, and sulphatase activity. Experiments with authentic $\triangle U A$ GalNAc-4S and $\triangle U A$ GalNAc-6S demonstrated that $\triangle U A$ GalNAc-4S rather than $\triangle U A$ GalNAc-6S was the preferred substrate for the sulphatase. Therefore, it is suggested that the CS-AC depolymerase of $S$. intermedius may play a role in the destruction of CS in host tissues, facilitating bacterial spread, and also in bacterial nutrition by the liberation of nutrients at the site of infection.
\end{abstract}

\section{Introduction}

The 'Streptococcus milleri group' which includes $S$. intermedius, $S$. constellatus and $S$. anginosus [1] forms part of the normal flora of the mouth, gastrointestinal tract and genitourinary tract and is often associated with purulent infections [2-4]. The tendency of members of the ' $S$. milleri group' to be associated with abscess formation in a variety of body sites, although well documented, remains largely unexplained. Interest has focused on the production of extracellular enzymes with the ability to damage host tissues, including hyaluronidase and chondroitin sulphate (CS) depolymerising enzymes, because of the

Received 21 July 1995; revised version accepted 5 Oct. 1995.

Corresponding author: Dr H. Shain apparent association between the production of these glycosaminoglycan (GAG) depolymerising enzymes and pathogenicity of the 'S. milleri group' $[5,6]$.

GAGs are a group of linear polysaccharides composed of repeating disaccharide units. Based on differences in monosaccharide moieties and the degree and position of sulphation, five classes are recognised: chondroitin sulphate, dermatan sulphate, heparan sulphate, keratan sulphate and the non-sulphated hyaluronic acid. These macromolecules interact with other fibrous proteins to form an extracellular matrix that maintains the structural integrity of host tissues [7]. The ability to produce GAG depolymerising enzymes has been considered to be a potential virulence determinant in organisms such as $S$. pneumoniae, staphylococci and Clostridium perfringens [8-10]. These enzymes may play a role in the pathogenic process by acting as 
bacterial 'spreading' factors facilitating local tissue spread of the organisms. In contrast to mammalian enzymes that depolymerise GAGs in a hydrolytic fashion, bacterial GAG depolymerising enzymes cleave hexosaminyl-hexuronyl linkages of GAGs by a $\beta$ elimination reaction leading to the formation of products with an unsaturated double bond in the 4,5position of the hexuronyl moiety [11-13].

Previous studies have demonstrated the production of hyaluronidase or CS depolymerase, or both, by members of the ' $S$. milleri group' $[5,6,14,15]$. However, following recent changes in the taxonomy of this group [1], Homer et al. [16], attempted to detect hyaluronidase and CS depolymerase production by representatives of each of the currently recognised species of viridans streptococci with a sensitive and quantitative spectrophotometric assay. Both $S$. intermedius and $S$. constellatus degraded hyaluronic acid but only S. intermedius produced CS depolymerase. The production of these GAG depolymerising enzymes by $S$. intermedius is of interest because this species, in particular, is strongly associated with brain and liver abscesses [17, 18].

Hyaluronate, when used as the sole carbohydrate supplement to minimal media, has been shown to support the growth of $S$. intermedius [19] but the degradation and utilisation of CS by $S$. intermedius has not been reported. Therefore the ability of $S$. intermedius to utilise CS as the sole source of carbohydrate was studied, as this might provide an insight into the association between $S$. intermedius and deep-seated purulent infections.

\section{Materials and methods}

\section{Growth and maintenance of $S$. intermedius}

$S$. intermedius strain UNS 35, a brain abscess isolate obtained from Dr P. Unsworth (Central Public Health Laboratory, 61 Colindale Avenue, London), was stored frozen on glass beads (Technical Service Consultants) at $-70^{\circ} \mathrm{C}$. Routine subculturing was performed on Fastidious Anaerobe Agar (Lab M) containing defibrinated horse blood $5 \% \mathrm{v} / \mathrm{v}$ (FAA) with incubation at $37^{\circ} \mathrm{C}$ in an anaerobic atmosphere $\left(\mathrm{H}_{2} 5 \%, \mathrm{CO}_{2} 10 \%\right.$, $\mathrm{N}_{2} 85 \%$ ).

\section{Growth in semi-defined media}

A modification of a semi-defined medium was used in all growth studies [20]. The basal medium contained sodium acetate $30 \mathrm{~g}$, casein hydrolysate (Oxoid) $25 \mathrm{~g}$, anhydrous $\mathrm{Na}_{2} \mathrm{HPO}_{4} 15.75 \mathrm{~g}$, anhydrous $\mathrm{NaH}_{2} \mathrm{PO}_{4}$ $10.25 \mathrm{~g}$, ammonium sulphate $3 \mathrm{~g}, \mathrm{KH}_{2} \mathrm{PO}_{4} 2.2 \mathrm{~g}$, $\mathrm{K}_{2} \mathrm{HPO}_{4} 1.5 \mathrm{~g}$, trisodium citrate $1.125 \mathrm{~g}$, adenine $0.15 \mathrm{~g}$, uracil $0.15 \mathrm{~g}$, guanine $0.1 \mathrm{~g}$, ferrous sulphate $0.05 \mathrm{~g}$, manganous sulphate $0.05 \mathrm{~g}$ and $\mathrm{NaCl} 0.05 \mathrm{~g}$ in distilled water $5.0 \mathrm{~L}$. All chemicals were purchased from Sigma. The medium was dispensed into 1-L volumes and sterilised by autoclaving at $121^{\circ} \mathrm{C}$ for $15 \mathrm{~min}$. Immediately prior to use, filter-sterilised solutions $\left(0.2-\mu \mathrm{m}\right.$ pore size filters) of $\mathrm{MgSO}_{4}$, cysteine- $\mathrm{HCl}$, and $\mathrm{Na}_{2} \mathrm{CO}_{3}$ were added to final concentrations of $0.20,0.25$ and $2.2 \mathrm{~g} / \mathrm{L}$, respectively, along with $1.0 \mathrm{ml}$ of a filter-sterilised vitamin solution. The vitamin solution contained nicotinamide $40 \mathrm{mg}$, pantothenate $16 \mathrm{mg}$, pyridoxamine $16 \mathrm{mg}$, riboflavin $8 \mathrm{mg}$, thiamine $8 \mathrm{mg}$, biotin $0.2 \mathrm{mg}$, folic acid $2.0 \mathrm{mg}$ and $p$-aminobenzoate $2.0 \mathrm{mg}$ in $20 \mathrm{ml}$ of distilled water. The medium was dispensed into sterile screwcapped containers in 10-ml volumes.

Chondroitin sulphate A (CS-A, Sigma) and chondroitin sulphate C (CS-C, Sigma) were used in the growth studies. The CS-A preparation as supplied consisted of CS-A:CS-C (70:30) and CS-C consisted of CS-A:CSC (10:90). The two types of CS differ in that CS-A is sulphated at the 4-position and CS-C is sulphated at the 6-position on the $\mathrm{N}$-acetylgalactosamine moiety. The presence of both 4- and 6-sulphated residues in the commercial preparations are due not only to the difficulty of separating the two types of CS but also to the fact that most CS molecules are hybrid structures containing both CS-A and CS-C residues [21].

Filter-sterilised stock solutions of CS-A and CS-C, each at $40 \mathrm{mg} / \mathrm{ml}$, and glucose at $20 \mathrm{mM}$ were prepared. The stock solutions were added to the basal medium to give a final volume of $20 \mathrm{ml}$ and the following concentrations of carbohydrate sources: CSA $20 \mathrm{mg} / \mathrm{ml}$; CS-C $20 \mathrm{mg} / \mathrm{ml}$; $10 \mathrm{mM}$ glucose, CS-A $10 \mathrm{mg} / \mathrm{ml}$ and $5 \mathrm{mM}$ glucose; CS-C $10 \mathrm{mg} / \mathrm{ml}$ and $5 \mathrm{mM}$ glucose. Media were pre-reduced prior to inoculation with $1 \mathrm{ml}$ of a late exponential phase culture of $S$. intermedius grown in Brain Heart Infusion Broth (BHI; Oxoid) for 3-4 h. The cultures were placed on a rotating drum (26 rotations $/ \mathrm{min}$ ) and incubated at $37^{\circ} \mathrm{C}$ in an anaerobic atmosphere. Growth was monitored over a $16 \mathrm{~h}$ period by removing $200-\mu \mathrm{l}$ samples of each culture at intervals and measuring the increase in optical density at $620 \mathrm{~nm}$ in flat-bottomed 96-well microtitration trays with a microtitration plate reader (Titertek Multiscan MCC-340; ICN-Flow Laboratories Ltd). Bacterial doubling times were calculated as described by Meynell and Meynell [22]. Additional samples $(1 \mathrm{ml})$ were removed at intervals into microcentrifuge tubes; the cells were pelleted by centrifugation $(13000 \mathrm{rpm}, 15 \mathrm{~min}$, MSE Microfuge) and culture supernate were stored at $-20^{\circ} \mathrm{C}$ for the subsequent analysis of residual substrates and metabolic end-products.

All cultures were set up in duplicate and all assays (except the 232-nm spectrophotometric assay method, see below) for media constituents or metabolic endproducts were performed in duplicate for each culture, with the data being presented as the mean of the four determinations. 


\section{Estimation of glucose and metabolic end-products}

Glucose concentrations were estimated with Sigma kit No. 510. The $\mathrm{A}_{450}$ was determined and glucose concentrations were calculated by comparison with a standard curve obtained with glucose in distilled water (linear up to $1 \mathrm{mM}$ ). Lactate was determined with Sigma kit No. 826. The increase in absorbance at $340 \mathrm{~nm}$ was measured and the $A_{340}$ at the end-point of the reaction was used to determine lactate concentrations with reference to standard lactate solutions prepared in distilled water (linear up to $10 \mathrm{mM}$ ). Ethanol was determined with a commercial diagnostic alcohol reagent kit (Sigma); the increase in absorbance at $340 \mathrm{~nm}$ was directly proportional to ethanol concentration up to an absorbance of 2.0. Formic acid was determined with a commercial kit (Boehringer Mannheim); the increase in absorbance at $340 \mathrm{~nm}$ was measured and formate concentration was' calculated according to the manufacturer's instructions.

\section{Determination of residual glycosaminoglycan}

Residual CS was determined by the Stains-all method of Homer et al. [23]. The Stains-all solution contained 1-ethyl-2-[3-(1-ethylnaphtho-[1, 2-d]thiazolin-2ylidene)-2-methylpropenyl]-naphtho-[1,2-d] thiazolium bromide (Sigma) and was prepared after the method of Benchetrit et al. [24]. The dye was dissolved to a final concentration of $0.1 \mathrm{mM}$ in water: 1,4-dioxan (50:50 $\mathrm{v}: \mathrm{v})$ containing $1 \mathrm{mM}$ acetic acid and $0.5 \mathrm{mM}$ ascorbic acid. 1,4-Dioxan (AnalaR, BDH Ltd, Poole, Dorset) contained 2,6-di-tert-butyl-4 methyl phenol c. $25 \mathrm{ppm}$ as a stabilising agent. Residual CS concentrations in culture supernates were estimated by mixing $20 \mu$ l of sample (appropriately diluted with distilled water) with $180 \mu 1$ of the Stains-all solution and $100 \mu \mathrm{l}$ of distilled water in microtitration trays and determining $\mathrm{A}_{450}$ within $5 \mathrm{~min}$. CS solutions, in distilled water gave a linear response over the concentration range up to $200 \mu \mathrm{g} / \mathrm{ml}$ when treated in the same manner and were included as standards.

\section{Determination of $\mathrm{N}$-acetylgalactosamine equivalents}

The supernatant concentrations of $\mathrm{N}$-acetylgalactosamine (GalNAc) equivalents, GalNAc moieties at the reducing terminal of saccharide species generated by the action of CS depolymerase, were estimated by a modification of the method of Levvy and McAllan [25]. The reagent consisted of concentrated $\mathrm{HCl} 11 \mathrm{ml}$, distilled water $1.5 \mathrm{ml}$, glacial acetic acid $87.5 \mathrm{ml}$ and 4(N,N-dimethylamino)-benzaldehyde (Sigma) $10 \mathrm{~g}$. Immediately prior to use, $10 \mathrm{ml}$ of the reagent were diluted to $100 \mathrm{ml}$ with glacial acetic acid. Samples $(125 \mu 1)$ were added to $25 \mu 1$ of $0.2 \mathrm{M}$ dipotassium tetraborate in a microcentrifuge tube and placed in a boiling water bath for $3 \mathrm{~min}$. Samples were cooled to room temperature, $750 \mu \mathrm{l}$ of the diluted reagent were added and the samples were incubated at $37^{\circ} \mathrm{C}$ for $20 \mathrm{~min}$. The treated samples were cooled to room temperature, 200- $\mu$ l volumes of each were dispensed into a microtitration tray and $\mathrm{A}_{540}$ was determined. The concentration of reducing terminal GalNAc in culture supernate was estimated by comparison with a series of standard GalNAc concentrations up to $10 \mathrm{mM}$, prepared in distilled water.

\section{Spectrophotometric assay for determination of 4,5-unsaturated disaccharides}

The presence of 4,5-unsaturated disaccharides was determined by a modification of the method of Saito et al. [26]. The unsaturated disaccharides have an absorbance maximum in the ultraviolet range $(232 \mathrm{~nm})$ at pH 2. Enriched Tris Buffer (ETB, pH 8.0) was prepared by dissolving tris (hydroxymethyl)aminomethane $3 \mathrm{~g}$, sodium acetate $2.4 \mathrm{~g}, \mathrm{NaCl} 1.46 \mathrm{~g}$ and crystalline bovine serum albumin (Sigma) $50 \mathrm{mg}$ in $100 \mathrm{ml}$ of $0.13 \mathrm{M} \mathrm{HCl}$. Samples of culture supernate $(40 \mu \mathrm{l})$ were added to $10 \mu \mathrm{l}$ of ETB in a microcentrifuge tube and incubated at $37^{\circ} \mathrm{C}$ for $30 \mathrm{~min}$. To this reaction mixture, $950 \mu \mathrm{l}$ of $0.01 \mathrm{M} \mathrm{HCl}$ were added and the absorbance of each treated sample was measured in a quartz cuvette at $232 \mathrm{~nm}$ with a Shimadzu UV 160-A recording spectrophotometer. The units for this assay were $\Delta \mathrm{A}_{232}$ relative to the control assay.

\section{Preparation of enzyme extracts}

A portion $(25 \mathrm{ml})$ of a late exponential phase culture of $S$. intermedius grown in BHI was used to inoculate $500 \mathrm{ml}$ of basal medium supplemented with either glucose (final concentration $10 \mathrm{mM}$ ) or CS-A (final concentration $5 \mathrm{mg} / \mathrm{ml}$ ). The cultures were incubated anaerobically at $37^{\circ} \mathrm{C}$ with constant stirring for $18 \mathrm{~h}$. Cells were harvested by centrifugation $(10000 \mathrm{rpm}$, $20 \mathrm{~min}, 4^{\circ} \mathrm{C}$ ) and supernates were decanted. Ammonium sulphate ( $80 \%$ saturation) was added to each of the culture supernates with gentle stirring at $4^{\circ} \mathrm{C}$. After $18 \mathrm{~h}$ at $4^{\circ} \mathrm{C}$, the solutions were centrifuged at $15000 \mathrm{rpm}$ for $1 \mathrm{~h}$ at $4^{\circ} \mathrm{C}$. The precipitates were dissolved in a minimal volume of ice-cold $50 \mathrm{~mm}$ sodium phosphate buffer, $\mathrm{pH} 7.0$, and dialysed against three changes of the same buffer at $4^{\circ} \mathrm{C}$. The dialysates were divided into small volumes and stored at $-20^{\circ} \mathrm{C}$.

The cell pellets were washed twice by centrifugation

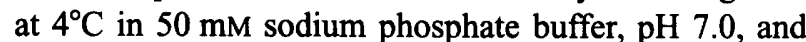
disrupted by shaking with glass beads (Ballotini No. 12 , Jencons) for $15 \mathrm{~min}$ at $4^{\circ} \mathrm{C}$ in a tissue disintegrator (Mickle Engineering Co.). Cell debris was removed by centrifugation $\left(13000 \mathrm{rpm}, 5 \mathrm{~min}, 4^{\circ} \mathrm{C}\right)$ and the cellfree extracts were stored at $-20^{\circ} \mathrm{C}$.

\section{Determination of protein concentrations}

The protein content of concentrated culture supernates and cell extracts was determined by the Coomassie 
Blue dye-binding assay (Sigma) and by comparison with a standard curve of bovine serum albumin $(0$ $500 \mu \mathrm{g} / \mathrm{ml})$.

\section{HPAEC-PAD quantification of 4,5-unsaturated disaccharides}

The concentrations of 2-acetamido-2-deoxy-3-O-( $\beta$-Dgluco-4- $\Delta$ enepyranosyluronic acid)-4-O-sulpho-D-galactose ( $\triangle \mathrm{UA}$ GalNAc-4S), 2-acetamido-2-deoxy-3-O$(\beta$-D-gluco-4- $\Delta$ enepyranosyluronic acid)-6-O-sulpho-Dgalactose ( $\triangle \mathrm{UA}$ GalNAc-6S) and 2-acetamido-2-deoxy3-O-( $\beta$-D-gluco-4- $\Delta$ enepyranosyluronic acid)-D-galactose ( $\triangle \mathrm{UA}$ GalNAc-0S) in culture supernates were measured by high $\mathrm{pH}$ anion exchange chromatography with pulsed amperometric detection (HPAEC-PAD) by a modification of the method of Shibata et al. [27]. Prior to analysis the unsaturated disaccharides in culture supernates were stabilised to alkali conditions by borohydride reduction. Briefly, samples of culture supernates were centrifuged $(13000 \mathrm{rpm}$ for $90 \mathrm{~min})$ through a Micron 3 microconcentrator with a $10 \mathrm{kDa}$ cut-off (Amicon Ltd). Sodium borohydride solution $\left(100 \mu l\right.$ of $1 \mathrm{M} \mathrm{NaBH}_{4}$ in $\left.100 \mathrm{mM} \mathrm{NaOH}\right)$ was added to $500 \mu \mathrm{l}$ of ultrafiltrate to give final concentration of $200 \mathrm{mM} \mathrm{NaBH}_{4}$. The borohydride reduction reaction was performed at room temperature for $1 \mathrm{~h}$ and was terminated by the addition of $180 \mu \mathrm{l}$ of $1 \mathrm{M}$ acetic acid to the sample placed on ice. A $100-\mu \mathrm{l}$ sample of each reduced sample was diluted with $400 \mu \mathrm{l}$ of $0.1 \mathrm{M} \mathrm{NaOH}$ and this was subjected to HPAEC-PAD analysis for the determination of concentrations of individual disaccharides.

Separation and quantification of CS-derived disaccharides was performed with a Dionex DX-500 chromatography system (Dionex Corporation, Sunnyvale, CA, USA) equipped with a Dionex Carbopac PA 100 column $(10 \mu \mathrm{m}, 250 \mathrm{~mm} \times 4 \mathrm{~mm}$ i.d.) fitted with a guard column (Dionex, PA100). Samples $(500 \mu \mathrm{l})$ were transferred to sample vials (Dionex) fitted with $20-\mu \mathrm{m}$ filters and injected with an autosampler. The column was equilibrated in $0.1 \mathrm{M}$ sodium acetate in $0.1 \mathrm{M}$ $\mathrm{NaOH}$ at a flow rate of $1.0 \mathrm{ml} / \mathrm{min}$ for $10 \mathrm{~min}$ before injection of sample ( $25 \mu 1$ sample loop). Separation of the disaccharides ( $\triangle$ UA GalNAc-4S, $\triangle$ UA GalNAc-6S and $\triangle$ UA GalNAc-0S) was achieved with a linear gradient of sodium acetate $(0.1-1.0 \mathrm{M})$ in $0.1 \mathrm{M} \mathrm{NaOH}$ over $90 \mathrm{~min}$, followed by isocratic elution with $1.0 \mathrm{M}$ sodium acetate in $0.1 \mathrm{M} \mathrm{NaOH}$ for $10 \mathrm{~min}$. It was necessary to re-equilibrate the column for $10 \mathrm{~min}$ under the starting conditions before application of a subsequent sample.

Eluted disaccharides were detected by a pulsed amperometric detector (PAD, Dionex) fitted with a gold working electrode. Peak areas were calculated with the DX-500 data handling system and concentrations of individual disaccharides were calculated by comparison with standard curves produced with authentic samples of $\triangle \mathrm{UA}$ GalNAc-4S, $\triangle \mathrm{UA}$ GalNAc-6S and $\triangle$ UA GalNAc-0S (Dextra Laboratories), over the concentration range $0-200 \mu \mathrm{g} / \mathrm{ml}$, reduced and treated as described above.

\section{Measurement of sulphatase activity}

The ability of the concentrated supernate preparations to desulphate the authentic unsaturated disaccharides, $\triangle U A$ GalNAc-4S and $\triangle U A$ GalNAc-6S derived, respectively from CS-A and CS-C, was determined. Reaction mixtures contained concentrated culture supernate $(20 \mu \mathrm{l}), 0.2 \mathrm{M}$ sodium phosphate buffer, $\mathrm{pH}$ $7.0(30 \mu \mathrm{l})$ and $\triangle \mathrm{UA}$ GalNAc-4S or $\Delta \mathrm{Ua}$ GalNAc-6S $2 \mathrm{mg} / \mathrm{ml}(50 \mu \mathrm{l})$. Separate samples were prepared for times 0,2 and $6 \mathrm{~h}$ and incubated at $37^{\circ} \mathrm{C}$. Assays were heated for $10 \mathrm{~min}$ in a boiling water bath to inactivate the enzyme, ultrafiltered and reduced as described previously and the concentration of the residual disaccharides was determined by HPAEC-PAD.

\section{Results}

\section{Growth of S. intermedius UNS 35}

Growth of $S$. intermedius in the presence of glucose was rapid with a doubling time of $1.3 \mathrm{~h}$ (Fig. 1a); glucose was completely utilised by $5 \mathrm{~h}$. In minimal medium containing CS-A as the sole carbohydrate source, bacterial growth was not detected until the concentration of reducing terminal GalNAc was increased to $c$. $2 \mathrm{mM}$, probably indicative of CS-A depolymerisation (Fig. 1b). The doubling time of the organism on CS-A in the period of exponential growth was $3.6 \mathrm{~h}$. The bacterial growth with the combination of glucose and CS-A is shown in Fig. 1c; glucose utilisation was rapid with a concomitant increase in absorbance and the doubling time was $1.2 \mathrm{~h}$. Following the utilisation of glucose the absorbance of the culture continued to increase slowly which is in contrast to the decrease in absorbance observed in the cultures with glucose alone upon the complete utilisation of glucose from the medium. The CS-A concentration was $10 \mathrm{mg}$ / $\mathrm{ml}$ and the utilisation of this no doubt contributed to the continued growth of the cells in the absence of glucose. No growth occurred when $S$. intermedius was grown in medium containing CS-C but in the medium supplemented with CS-C and glucose the strain grew with a doubling time of $1.4 \mathrm{~h}$ (data not shown).

Cells grown in the presence of glucose produced only lactate as the major end-product of metabolism, whereas cells grown in the presence of glucose and CS-A produced a mixture of lactate, formate and ethanol. The formation of acetate could not be demonstrated due to the formulation of the basal medium. S. intermedius grown with CS-A produced ethanol and formate, but not lactate as the major endproducts (Table 1). After growth for $16 \mathrm{~h}$, a reduction in the concentration of CS-A was demonstrable (by 

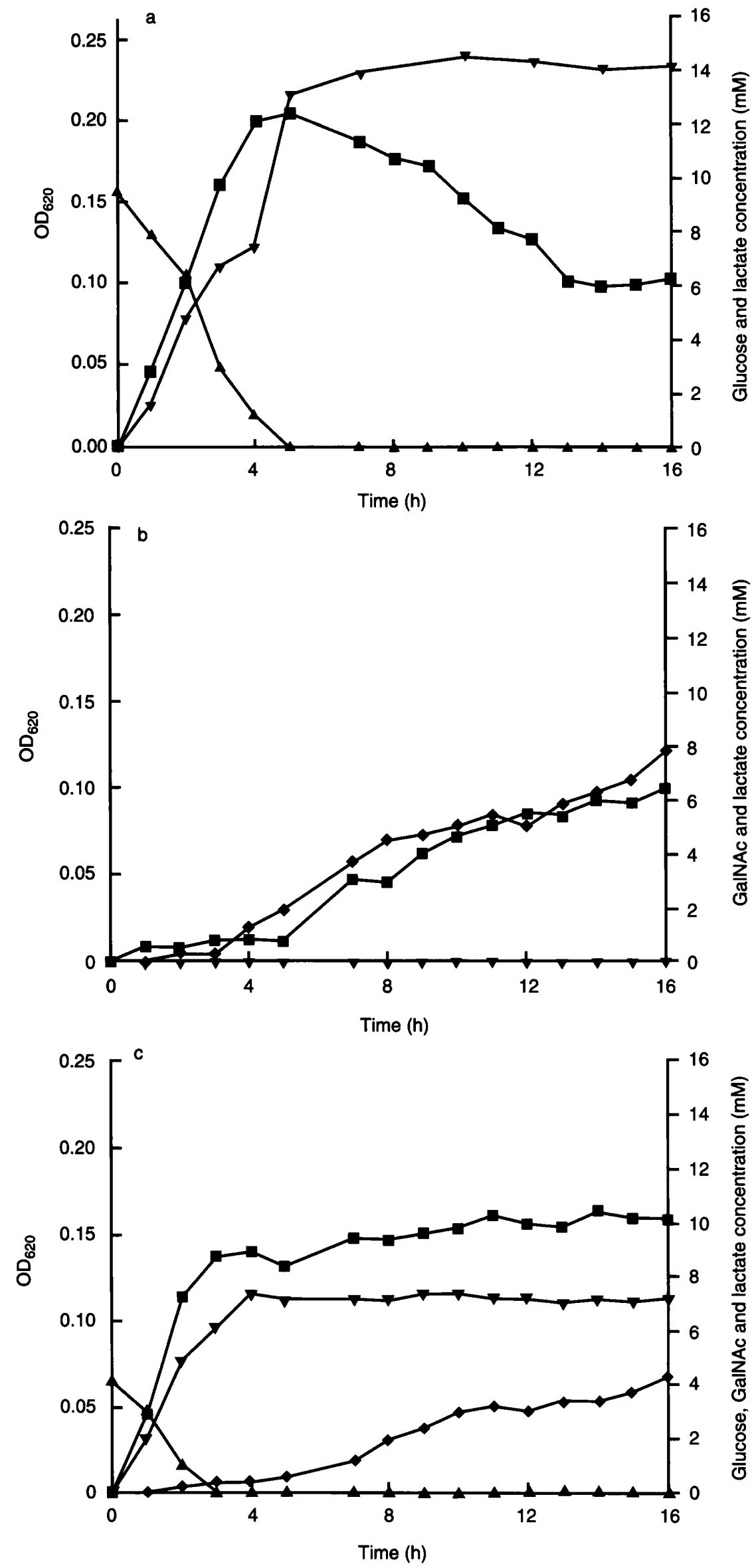

Fig. 1. Growth characteristics of $S$. intermedius UNS 35 in semi-defined media supplemented with: a $10 \mathrm{mM}$ glucose b, CS-A $20 \mathrm{mg} / \mathrm{ml}$; c, $5 \mathrm{mM}$ glucose and CS-A $10 \mathrm{mg} / \mathrm{ml}$. The cultures were incubated anaerobically at $37^{\circ} \mathrm{C}$ and samples were taken at the times indicated for determination of optical density $(\boldsymbol{\square})$, glucose utilisation $(\boldsymbol{\Delta})$, production of lactate $(\boldsymbol{\nabla})$ and $\mathrm{N}$-acetylamino sugar $(\boldsymbol{\nabla})$. 
Table 1. Characteristics of glucose, CS-A and CS-C metabolism by $S$. intermedius after anaerobic incubation at $37^{\circ} \mathrm{C}$ for $16 \mathrm{~h}$

\begin{tabular}{|c|c|c|c|c|c|c|}
\hline $\begin{array}{l}\text { Substrate added to } \\
\text { basal medium }\end{array}$ & $\begin{array}{c}\mathrm{CS} \\
\text { utilised } \\
(\mathrm{mg} / \mathrm{ml})\end{array}$ & $\begin{array}{c}\text { GalNAc } \\
\text { formed } \\
(\mathrm{mM})\end{array}$ & $\begin{array}{c}\mathbf{A}_{232} \\
\text { assay } \\
\Delta \mathbf{A}_{232}\end{array}$ & $\begin{array}{c}\text { Lactate } \\
\text { formed } \\
(\mathrm{mM})\end{array}$ & $\begin{array}{l}\text { Ethanol } \\
\text { formed } \\
\text { (mM) }\end{array}$ & $\begin{array}{c}\text { Formate } \\
\text { formed } \\
\text { (mM) }\end{array}$ \\
\hline Glucose $(10 \mathrm{mM})$ & nd & nd & nd & 14.12 & 0 & 0 \\
\hline CS-A $(20 \mathrm{mg} / \mathrm{ml})$ & 5.08 & 7.82 & 0.50 & 0 & 2.00 & 7.67 \\
\hline $\mathrm{CS}-\mathrm{C}(20 \mathrm{mg} / \mathrm{ml})$ & 0.00 & 0.06 & 0.07 & 0 & nd & nd \\
\hline \multicolumn{7}{|l|}{ Glucose $(5 \mathrm{mM})$} \\
\hline and $\mathrm{CS}-\mathrm{A}(10 \mathrm{mg} / \mathrm{ml})$ & 1.20 & 4.25 & 0.47 & 6.66 & 0.14 & 2.61 \\
\hline \multicolumn{7}{|l|}{ Glucose $(5 \mathrm{mM})$ and } \\
\hline CS-C $(10 \mathrm{mg} / \mathrm{ml})$ & 0 & 0.17 & 0.02 & 5.90 & nd & nd \\
\hline
\end{tabular}

nd, not determined.

the Stains-all assay) while no change in the concentration of CS-C was observed in either of the CS-Csupplemented cultures. Similarly, after $16 \mathrm{~h}$ there was an increase in the concentration of reducing terminal GalNAc and in the concentration of 4,5-unsaturated disaccharides (determined by the $232-\mathrm{nm}$ assay) in the cultures supplemented with CS-A, but these were present only at low levels in the CS-C supplemented cultures (Table 1).

\section{Breakdown products of CS-A by $S$. intermedius UNS 35}

The chemical assays used in this study are sensitive but not necessarily specific: the 232-nm assay does not distinguish between $\triangle U A$ GalNAc-4S (derived from CS-A), $\triangle$ UA GalNAc-6S (derived from CS-C) and $\triangle \mathrm{UA}$ GalNAc-0S, and the $\mathrm{N}$-acetylamino sugar assay gives a positive reaction with $\triangle U A$ GalNAc-6S and $\triangle U A$ GalNAc-0S but not with $\triangle U A$ GalNAc-4S [26]. As $S$. intermedius UNS 35 grew with CS-A but not with $\mathrm{CS}-\mathrm{C}$ and the $\mathrm{N}$-acetylamino sugar assay results paralleled the increase in cell numbers, HPAEC-PAD analysis was used to characterise and quantify the individual unsaturated disaccharides present in culture supernates during the growth of $S$. intermedius in the presence of CS-A.

The separation of $\triangle U A$ GalNAc- $0 S, \triangle U A$ GalNAc-4S and $\triangle \mathrm{UA}$ GalNAc-6S was readily achieved (Fig. 2a) and the detector response was linear for each disaccharide (Fig. 2b). The changes in the supernate concentration of the individual unsaturated disaccharides over a 16-h incubation period are shown in Fig. 3. The concentration of $\triangle U A$ GalNAc-0S increased in a linear fashion to a peak at $c .8 \mathrm{~h}$ and then, presumably as a consequence of bacterial growth, was gradually removed from the medium. $\triangle \mathrm{UA}$ GalNAc-6S was detectable at $4 \mathrm{~h}$ and its concentration rose progressively, paralleling cell production, reaching a maximum at $14 \mathrm{~h}$ after which the concentration remained level. The changes in the concentrations of $\triangle U A$ GalNAc-0S and $\triangle U A$ GalNAc$6 \mathrm{~S}$ are in contrast to the behaviour of $\triangle \mathrm{UA}$ GalNAc$4 \mathrm{~S}$, the major breakdown product of CS-A, which accumulated only slowly in the medium (Fig. 3). The initial rise of GalNAc (Fig. 1b) was due to the accumulation of $\triangle \mathrm{UA}$ GalNAc-0S, and after $8 \mathrm{~h} \Delta \mathrm{UA}$ GalNAc-6S, derived from CS-C, was the predominant unsaturated disaccharide, which suggests that bacterial growth was a consequence of the utilisation of $\Delta U A$ GalNAc-0S.

The presence of both sulphated ( $\Delta \mathrm{UA}$ GalNAc-6S, $\triangle U A$ GalNAc-4S) and non-sulphated ( $\triangle U A$ GalNAc$0 S$ ) unsaturated disaccharides in these cultures indicates the production, by $S$. intermedius, of CS-AC depolymerase and sulphatase activities.

\section{Location and induction of CS depolymerase}

The CS depolymerase activity associated with bacteria and in the culture supernate was measured after growing bacteria in minimal medium supplemented with either glucose or CS-A. Culture supernates were concentrated before performing these assays as the level of activity in untreated culture supernates was too low to be measured reliably. CS depolymerase activity was detected in the culture supernate of minimal medium with glucose $(1.24 \mathrm{mg}$ of CS-A degraded $/ \mathrm{h} / \mathrm{mg}$ of protein) but activity was much higher in the supernate with CS-A $(34.20 \mathrm{mg}$ of CS-A degraded/h/ $\mathrm{mg}$ of protein). CS depolymerase activity was associated with cells grown in media containing CS-A but this was only $0.3 \%$ of the supernate activity, which was similar to the proportion $(0.4 \%)$ present in the cells grown with glucose.

\section{Measurement of sulphatase activity}

Preliminary experiments were performed with authentic $\triangle \mathrm{UA}$ GalNAc-4S and $\Delta \mathrm{UA}$ GalNAc-6S to determine which of these was the preferred substrate for the $S$. intermedius sulphatase activity to identify the origin of the $\triangle \mathrm{UA}$ GalNAc-0S detected in the culture supernate of bacteria grown with CS-A. The rates of loss of $\triangle U A$ GalNAc-4S and $\triangle U A$ GalNAc-6S were $>370$ and $70 \mu \mathrm{mol} / \mathrm{h} / \mathrm{mg}$ of protein, respectively, indicating that the majority of $\triangle U A$ GalNAc-0S was derived from the desulphation of $\triangle \mathrm{UA}$ GalNAc-4S, the 4,5-unsaturated disaccharide produced as a result of CS-A depolymerisation by $S$. intermedius. 


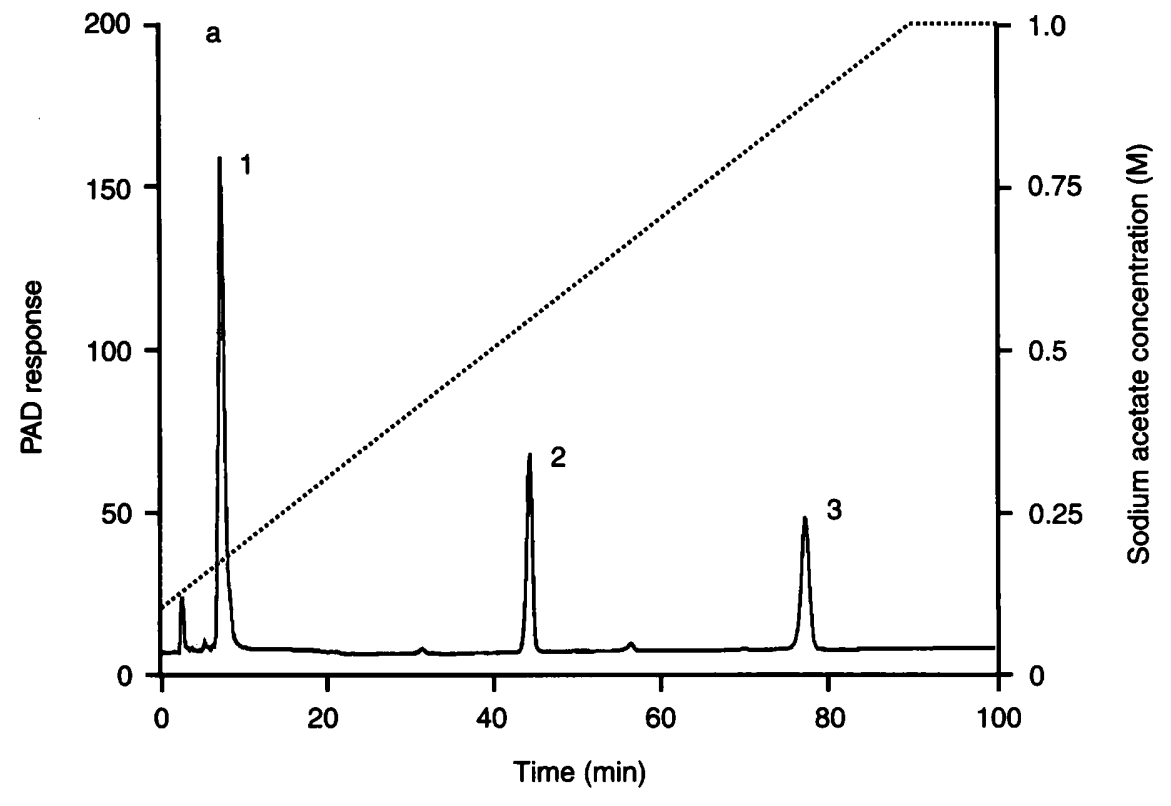

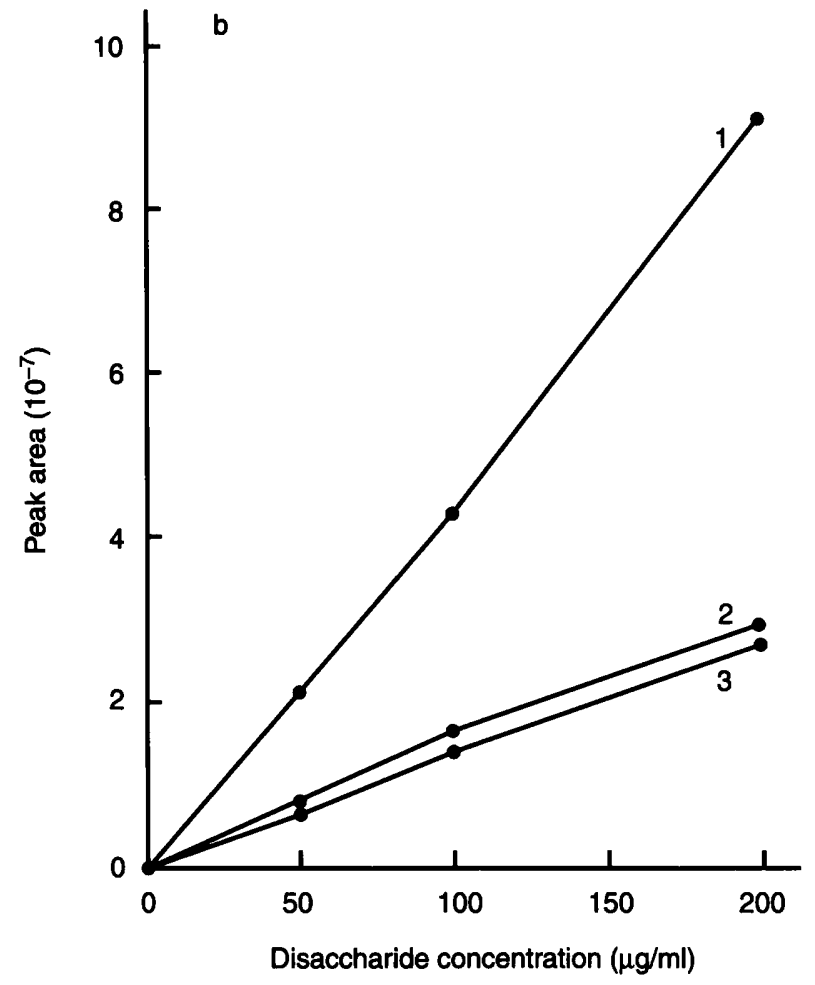

\section{Discussion}

$S$. intermedius is unique amongst the viridans steptococci in its ability to produce CS depolymerase activity. Previous investigations into the substrate specificity of this enzyme activity have tended to suggest that $S$. intermedius has the ability to degrade CS-C $[14,28]$, whereas in a study of 10 strains of $S$. intermedius, CS-A but not CS-C was depolymerised [16]. In these studies a rich, complex medium (BHI) containing glucose and supplemented with the appropriate form of CS was used. The data presented in this study provide an explanation for the apparent discrepancies between these previous reports.
Fig. 2. HPAEC-PAD identification and quantitation of unsaturated disaccharides derived from CS. a, Separation of $\triangle \mathrm{UA}$ GalNAc-0S (1), $\triangle \mathrm{UA}$ GalNAc-4S (2), $\Delta \mathrm{UA}$ GalNAc-6S (3) with Carbopac PA100. Samples $(25 \mu \mathrm{l})$ of authentic disaccharides at a final concentration of $100 \mu \mathrm{g} / \mathrm{ml}$ after sodium borohydride reduction were injected and eluted with a sodium acetate gradient as described in Materials and methods. b, Linearity of PAD response with varying disaccharide concentrations.

In the present study, CS-A, but not CS-C, sustained the growth of $S$. intermedius UNS 35. In these experiments the source of CS-A also contained $30 \% \mathrm{CS}-\mathrm{C}$ and, as a consequence of growth in CS-A-supplemented media, it was clear that $S$. intermedius depolymerised both CS$A$ and CS-C. This was apparent from the indirect chemical assays and from the direct measurement of 4,5-unsaturated disaccharides in culture supernates by HPAEC-PAD. The formation of the individual 4,5unsaturated disaccharides in the culture supernates provided information on the sequence of metabolic events involved in the depolymerisation and utilisation of CS-A. Although $\triangle \mathrm{UA}$ GalNAc-4S is the product derived initially from CS-A depolymerisation, the 


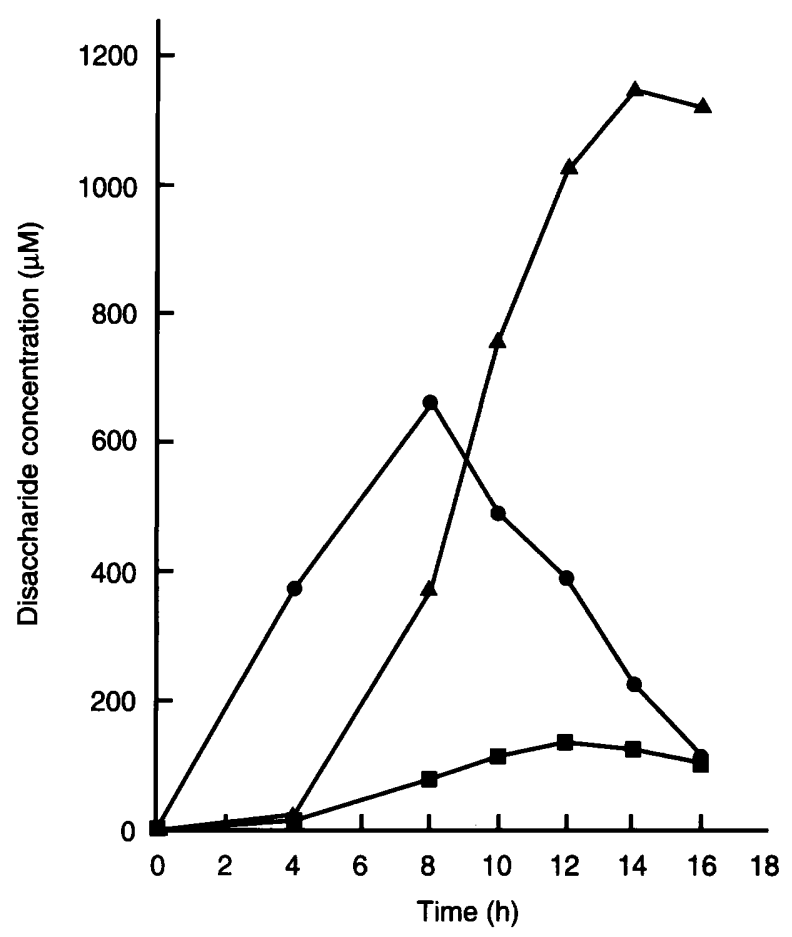

Fig. 3. Quantification of unsaturated disaccharides released from the breakdown of CS-A in the culture supernate of $S$. intermedius UNS 35 grown in a semidefined medium supplemented with CS-A as the major fermentable carbohydrate. Samples of culture supernate were taken at the times indicated (corresponding to data illustrated in Fig. 1) and $\triangle U A$ GalNAc-0S (-O), $\triangle U A$ GalNAc-4S ( $\mathbf{\square}), \Delta$ UA GalNAc-6S $(\boldsymbol{\Delta}-\mathbf{\Delta})$ concentrations were determined by HPAEC-PAD analysis.

concentration of $\triangle U A$ GalNAc-4S remained low throughout the growth period. However, there was a significant rise in the concentration of $\triangle U A$ GalNAc$O S$ in the culture supernate, while the concentration of $\triangle U A$ GalNAc-6S increased throughout the incubation period, indicating that the $\triangle U A$ GalNAc-4S, rather than $\triangle$ UA GalNAc-6S, was the preferred substrate for the sulphatase activity of $S$. intermedius and this was confirmed in experiments with authentic unsaturated disaccharides. Enzymes with sulphatase activity against CS-derived disaccharides have been demonstrated in other bacteria $[29,30]$. The chondrosulphatases of Proteus vulgaris have been shown to have a high degree of specificity for the 4- and 6-sulphate esters, respectively [30].

In streptococci, the formation of lactate as the major or sole acid end-product is indicative of carbon excess as reported here in the glucose-supplemented cultures. The formation of mixed fermentation products, by heterofermentative metabolism, as was found in the CS-A-supplemented cultures, is indicative of carbonlimited growth in streptococci $[31,32]$. The mechanism underlying the apparent carbon-limited growth in CS-A supplemented cultures is unknown.

The present observations provide an explanation for the apparent anomalies between the reports of Osano et al. [14] and Hibi et al. [28] and our own [16]. We reported that $S$. intermedius strains degraded CS-A in BHI broth but the studies of Osano et al. [14] indicated that $S$. intermedius produced CS-C depolymerase when grown on BHI agar supplemented with CS-C; enzyme activity was detected as described by Smith and Willet [33]. We have used this assay technique and found that, when $S$. intermedius UNS 35 was stabbed into the medium, with CS-A as the substrate, the zones of depolymerisation were $6 \mathrm{~mm}$ in diameter, whereas with CS-C the zones were smaller $(4 \mathrm{~mm})$ and less distinct (data not shown). Hibi et al. [28] also demonstrated that a partially purified enzyme produced from a culture of $S$. intermedius grown on BHI supplemented with CS-C apparently had only a CS-C activity after incubation for $48 \mathrm{~h}$. However, the present results demonstrate that $S$. intermedius depolymerised both CS-A and CS-C, but the resulting 4- and 6-sulphated disaccharides were subsequently desulphated at significantly different rates. As a result, prolonged incubation of a mixture of CS-A and CS-C with a partially purified enzyme preparation of $S$. intermedius is likely to result in the formation of $\triangle U A$ GalNAc-6S and $\triangle$ UA GalNAc-4S and the latter will be desulphated rapidly as reported here. The desulphated disaccharide ( $\triangle$ UA GalNAc-OS) may be further metabolised by an intracellular 'glucuronidase'-like activity $[11,12]$ released during supernate preparation. This sequence of events could explain why only $\triangle U A$ GalNAc-6S was detected by Hibi et al. [28]. Therefore, S. intermedius like many other bacterial species, produces a CS-AC depolymerase and not a specific CS-C depolymerase. Specific CS-C depolymerases are produced by only a few bacterial species [34].

The production of CS depolymerase by $S$. intermedius UNS 35 was inducible; little activity was produced by cells growing in the presence of glucose. This finding is consistent with the low level of production of polysaccharide-degrading enzymes by other bacteria when a more readily catabolisable substrate is available $[35,36]$. Also, a previous report has shown that exoglycosidic enzymes, (neuraminidase, $\beta$-galactosidase, $\beta$-N-acetylgalactosaminidase and $\beta$ - $\mathrm{N}$-acetylglucosaminidase) with the ability to degrade the oligosaccharide of human glycoproteins, are repressed in $S$. intermedius when glucose is provided as a carbohydrate source [37]. It is energetically unfavourable for micro-organisms to produce enzymes to liberate nutrients from larger molecules when a more readily available nutrient source is provided and this may explain the inducible nature of the CS depolymerase of $S$. intermedius.

In gram-negative bacteria, including Bacteroides thetaiotaomicron, $P$. vulgaris and Flavobacterium heparinum, CS depolymerase is apparently located in the periplasmic space $[30,38]$. However, we found that $>99 \%$ of the CS depolymerase activity of $S$. intermedius was in the culture supernate, with $<1 \%$ being cell-associated. These observations are in accord 
with those of Hibi et al. [28] who found CS-C depolymerase activity to be predominantly in the culture supernate.

CS is widely distributed throughout connective tissues and in most cases has a hybrid structure with both 4and 6-sulphate groups present in the same molecule [39]. The present study demonstrated that $S$. intermedius strain UNS35 produces CS depolymerase activity with the ability to depolymerise both CS-A and CS-C. The organism was better able to desulphate $\triangle U A$ GalNAc-4S, derived from CS-A, than $\triangle U A$ GalNAc-6S, derived from CS-C to yield $\triangle U A$ GalNAc-0S, which may be slowly metabolised to yield cell mass. Further investigations are required to characterise the CS depolymerase and sulphatase activities of $S$. intermedius and to understand the mechanism of transport and intracellular metabolism of $\triangle \mathrm{UA}$ GalNAc-0S. These findings indicate that CS depolymerase production by $S$. intermedius may play a role not only in the destruction of host connective tissue but also in bacterial nutrition by the release of nutrients, so that the organisms can thrive and persist in an otherwise nutritionally compromised infected site.

The Dionex DX-500 system was purchased with a grant from the Research Strategy Fund of King's College, London.

\section{References}

1. Whiley RA, Beighton D. Emended descriptions and recognition of Streptococcus constellatus, Streptococcus intermedius, Stretococcus anginosus as distinct species. Int $J$ Syst Bacteriol 1991; 41: 1-5.

2. Gossling J. Occurrence and pathogenicity of the Streptococcus milleri group. Rev Infect Dis 1988; 10: 257-285.

3. Parker MT, Ball LC. Streptococci and aerococci associated with systemic infection in man. $J$ Med Microbiol 1976; 9: 275-302.

4. Ruoff KL. Streptococcus anginosus ("Streptococcus milleri"): the unrecognized pathogen. Clin Microbiol Rev 1988; 1: 102108.

5. Ruoff KL, Ferraro MJ. Hydrolytic enzymes of "Streptococcus milleri”. J Clin Microbiol 1987; 25: 1645-1647.

6. Unsworth PF. Hyaluronidase production in Streptococcus milleri in relation to infection. $J$ Clin Pathol 1989; 42: 506-510.

7. Kjellen L, Lindahl U. Proteoglycans: structures and interactions. Annu Rev Biochem 1991; 60: 443-475.

8. Abramson C. Staphylococcal hyaluronidase isoenzyme profiles related to staphylococcal disease. Ann NY Acad Sci 1974; 236 : 495-507.

9. Paton JC, Andrew PW, Boulnois GJ, Mitchell TJ. Molecular analysis of the pathogenicity of Streptococcus pneumoniae: the role of pneumococcal proteins. Annu Rev Microbiol 1993; 47: 89-115.

10. Steffen EK, Hentges DJ. Hydrolytic enzymes of anaerobic bacteria isolated from human infections. J Clin Microbiol 1981; 14: $153-156$.

11. Kennedy JF. Proteoglycans - biological and chemical aspects in human life. Amsterdam, Elsevier Scientific Publishing Company. 1979: 195-223.

12. Linker A, Hoffman P, Meyer K, Sampson P, Korn ED. The formation of unsaturated disaccharides from mucopolysaccharides and their cleavage to $\alpha$-keto acids by bacterial enzymes. $J$ Biol Chem 1960; 235: 3061-3065.

13. Linker A, Meyer K, Hoffman P. The production of unsaturated uronides by bacterial hyaluronidases. $J$ Biol Chem 1956; 219: $13-25$.

14. Osano E, Hibi E, Ozeki M, Fujii Y, Moriyama T. Chondroitin sulfate-depolymerizing activity in Streptococcus intermedius and other streptococci. Microbiol Immunol 1987; 31: 1127-1130.

15. Whiley RA, Hardie JM. DNA-DNA hybridization studies and phenotypic characteristics of strains within the 'Streptococcus milleri group'. J Gen Microbiol 1989; 135: 2623-2633.

16. Homer KA, Denbow L, Whiley RA, Beighton D. Chondroitin sulfate depolymerase and hyaluronidase activities of viridans streptococci determined by a sensitive spectrophotometric assay. $J$ Clin Microbiol 1993; 31: 1648-1651.

17. Whiley RA, Beighton D, Winstanley TG, Fraser HY, Hardie JM. Streptococcus intermedius, Streptococcus constellatus, and Streptococcus anginosus (the Streptococcus milleri group): association with different body sites and clinical infections. $J$ Clin Microbiol 1992; 30: 243-244.

18. Whiley RA, Fraser H, Hardie JM, Beighton D. Phenotypic differentiation of Streptococcus intermedius, Streptococcus constellatus, and Streptococcus anginosus within the "Streptococcus milleri group". J Clin Microbiol 1990; 28: 1497-1501.

19. Homer KA, Grootveld MC, Hawkes J, Naughton DP, Beighton D. Degradation of hyaluronate by Streptococcus intermedius strain UNS 35. J Med Microbiol 1994; 41: 414-422.

20. Russell RRB. Comparison of oral Streptococcus mutans AHT with strains of serotypes $a$ and $g$ by biochemical and electrophoretic methods. Arch Oral Biol 1979; 24: 617-619.

21. Linn S, Chan T, Lipeski L, Salyers AA. Isolation and characterization of two chondroitin lyases from Bacteroides thetaiotaomicron. $J$ Bacteriol 1983; 156: 859-866.

22. Meynell GG, Meynell E. Theory and practice in experimental bacteriology, 2nd edn. Cambridge, Cambridge University Press. 1970.

23. Homer KA, Denbow L, Beighton D. Spectrophotometric method for the assay of glycosaminoglycans and glycosaminoglycandepolymerizing enzymes. Anal Biochem 1993; 214: 435-441.

24. Benchetrit LC, Pahuja SL, Gray ED, Edstrom RD. A sensitive method for the assay of hyaluronidase activity. Anal Biochem 1977; 79: 431-437.

25. Levvy GA, McAllan A. The $\mathrm{N}$-acetylation and estimation of hexosamines. Biochem $J$ 1959; 73: 127-132.

26. Saito H, Yamagata T, Suzuki S. Enzymatic methods for the determination of small quantities of isomeric chondroitin sulfates. $J$ Biol Chem 1968; 243: 1536-1542.

27. Shibata S, Midura RJ, Hascall VC. Structural analysis of the linkage region of oligosaccharides and unsaturated disaccharides from chondroitin sulfate using carboPac PA1. J Biol Chem 1992; 267: 6548-6555.

28. Hibi E, Osano E, Fujii Y, Moriyama T. Chondroitinase C activity of Streptococcus intermedius. FEMS Microbiol Lett 1989; 57: 121-124.

29. Lloyd AG. Chondrosulfatase from Proteus vulgaris. Methods Enzymol 1966; 8: 663-670.

30. Yamagata T, Saito $H$, Habuchi $O$, Suzuki S. Purification and properties of bacterial chrondroitinases and chondrosulfatases. $J$ Biol Chem 1968; 243: 1523-1535.

31. Yamada T, Carlsson J. Regulation of lactate dehydrogenase and change of fermentation products in streptococci. $J$ Bacteriol 1975; 124: 55-61.

32. Yamada T, Carlsson J. The role of pyruvate formate-lyase in glucose metabolism of Streptococcus mutans. In: Stiles HM, Loesche WJ, O'Brien TC (eds) Microbial aspects of dental caries, Washington, DC, Information Retrieval. 1976: 809-819.

33. Smith RF, Willett NP. Rapid plate method for screening hyaluronidase and chrondroitin sulfatase-producing microorganisms. Appl Microbiol 1968; 16: 1434-1436.

34. Michelacci YM, Dietrich CP. Chrondroitinase C from Flavobacterium heparinum. J Biol Chem 1976; 251: 1154-1158.

35. Salyers AA. Energy sources of major intestinal fermentative anaerobes. Am J Clin Nutr 1979; 32: 158-163.

36. Salyers AA, Kotanski SF. Induction of chondroitin sulfate lyase activity in Bacteroides thetaiotaomicron. $J$ Bacteriol 1980; 143: 781-788.

37. Homer KA, Whiley RA, Beighton D. Production of specific glycosidase activities by Streptococcus intermedius strain UNS35 grown in the presence of mucin. $J$ Med Microbiol 1994; 41: 184-190.

38. Salyers AA, O'Brien M. Cellular location of enzymes involved in chondroitin sulfate breakdown by Bacteroides thetaiotaomicron. J Bacteriol 1980; 143: 772-780.

39. Rodén L. Structure and metabolism of connective tissue proteoglycans. In: Lennarz WJ (ed) The biochemistry of glycoproteins and proteoglycans. New York, Plenum Press. 1980: $267-371$. 